\title{
PELATIHAN DAN PENGEMBANGAN KOMUNITAS TEKSTIL DI PIK PULO GADUNG DENGAN PENDEKATAN SISTEM PRODUKSI
}

\author{
Vincentius Daniel Christianto ${ }^{1}$, Suryono Herlambang ${ }^{2}$
}

1)Program Studi S1 Arsitektur, Fakultas Teknik, Universitas Tarumanagara, danil.123christianto@gmail.com

2) Program Studi S1 PWK, Fakultas Teknik, Universitas Tarumanagara, suryonoh@ft.untar.ac.id

\begin{abstract}
Abstrak
Kawasan industri Pulo Gadung adalah sebuah Kawasan industri yang berlokasi di Kota Jakarta Timur, Kelurahan Jatinegara, Kecamatan Cakung, Kota Jakarta Timur. Kawasan Perkampungan Industri Kecil Pulo Gadung merupakan hasil dari program relokasi industri kecil pada tahun 1981 dikarenakan pada tahun 1966 industri di wilayah Jakarta tidak mampu beroperasi secara maksimal karena situasi ekonomi yang terjadi pada jaman itu. Relokasi berada di Kawasan Pulo Gadung karena letak wilayahnya yang strategis dan dekat dengan jalan besar seperti jalan raya Klender-Bekasi yang memudahkan akses dalam memperoleh bahan baku dan proses pemasaran produk industri. Seiring meningkatnya para pendatang dan kurangnya pengendalian dalam pengelola industry kecil maka banyak orang tidak dapat memanfaatkan potensi yang ada dan kurangnya pelatihan sehingga berakhir dengan meningkatny pengangguran di kota kota besar. Permasalahan yang dijumpai dalam Kawasan industri Perkampungan Industri Kecil Pulogadung adalah tidak adanya lembaga pelatihan seputar industri dan sarana seperti galeri atau tempat untuk mempresentasikan produk industri tersebut sehingga para pendatang tidak dapat mengetahui lebih dalam mengenai hal hal seputar industri dan hasil akhir dari industri tersebut. Dominasi area Kawasan Perkampungan Industri Kecil dan pengaruhnya. Dilihat dari peta Kawasan PIK keadaan eksistingnya, Kawasan PIK Pulo Gadung didominasi oleh para pengusaha industri kecil dan perkampungan wilayah penggilingan, dengan banyaknya pengusaha industri kecil pada bidang tekstil maka untuk merespon wilayah sekitar perlu menyediakan wadah untuk memperlhatkan karya karya industri kecil dan menarik para pengunjung sekitar Kawasan.

Kata kunci: Industri kecil; PIK pulogadung; Tekstil
\end{abstract}

\begin{abstract}
Pulo Gadung industrial area is an industrial area located in East Jakarta, Jatinegara subdistrict, Cakung sub-district, East Jakarta city. The PIK Pulo Gadung area was the result of the small industry relocation program in 1981 because in 1966 the industry in the Jakarta area was unable to operate optimally due to the economic situation that occurred at that time. The relocation is in the Pulo Gadung area because of its strategic location and close to major roads such as the Klender-Bekasi highway which makes it easy to access raw materials and the process of marketing industrial products. Along with the increase in immigrants and the lack of control in managing small industries, many people cannot take advantage of the existing potential and lack of training so that it ends with increasing unemployment in big cities. The problem encountered in the Pulogadung Small Industrial Village industrial area is the absence of training institutions around the industry and facilities such as galleries or places to present industrial products so that newcomers cannot find out more about matters surrounding the industry and the final results of the industry. Domination of the Small Industrial Village Zone area and its influence. Judging from the map of the PIK Zone its existing condition, the PIK Pulo Gadung area is dominated by small industry entrepreneurs and milling villages, with many small industrial entrepreneurs in the textile sector, responding to the surrounding area, it is necessary to provide a forum to show the work of small industries and attract local visitors. Area
\end{abstract}

Keywords : PIK pulogadung, small industry, textile 


\section{PENDAHULUAN}

\section{Latar belakang}

Semakin meningkatnya perubahan dan kemajuan yang terjadi pada kota-kota besar membuat banyak orang ingin mencari pekerjaan pada kota besar yang disebut urbanisasi, namun di Indonesia urbanisasi mengalami kenaikan tiap tahunnya karena kepadataan penduduk yang tinggi sehingga berdampak pada berbagai hal seperti semakin tipisny lahan pekerjaan, meningkatnya lingkungan kumuh, kemiskinan dan ketidakmerataan pembangunan.

Dengan banyaknya orang yang berdatangan ke kota besar banyak terdapat Indsutri kecil seperti pada kegiatan industri kecil di pulogadung, penggilingan cakung. Namun seiring meningkatnya para pendatang dan kurangnya pengendalian dalam pengelola industri kecil maka banyak orang tidak dapat memanfaatkan potensi yang ada dan kurangnya pelatihan sehingga berakhir dengan meningkatny pengangguran di kota kota besar.

Hal yang dilakukan untuk memajukan antara industri dan pengangguran akibat tinggi nya arus urbanisasi adalah membuat suatu wadah komunitas untuk pelatihan ,workshop mengenai industri kecil dan membuat galeri pada acara tertentu sehingga dapat menciptakan lapangan pekerjaan baru dan meningkatkan kualitas dari hasil industri tersebut. mereka untuk berkumpul bersama di luar lingkungan tempat tinggal mereka dan melakukan hal-hal baru yang produktif dan mereka sukai, kemungkinan inilah yang memberikan peluang bahwa ruang komunitas akan dibutuhkan kedepannya.

\section{Rumusan Permasalahan}

Dari latar belakang tersebut,terdapat beberapa masalah yang ditemukan dan dapat menjadi bahan penelitian antara lain:

a. Bagaimana cara mengembangkan potensi dari industri kecil sehingga dilihat oleh masyarakat luas?

b. Bagaimana industri kecil dapat menciptakan lapangan pekerjaan baru ditingginya arus urbanisasi

c. Apa saja proses produksi yang ada dalam industry tekstil?

\section{Tujuan}

Tujuan dari proyek ini adalah untuk menciptakan lapangan pekerjaan baru di bidang industri tekstil dengan adanya workshop menjahit dan juga meningkatkan kemajuan industri kecil. Meningkatkan kreativitas dalam menciptakan suatu karya dan meningkatkan teknik dasar dalam industri tekstil.

\section{KAJIAN LITERATUR}

\section{Dwelling}

Dwelling merupakan suatu tempat tinggal yang memiliki jenis yang berbeda: alam, kompleks, publik dan pribadi dan ruang yang tercipta dari sekelompok bangunan. Menurut Martin Heidegger dalam tulisannya "building, dwelling, thinking" berpendapat bahwa cara kita tinggal/hidup adalah cara di mana kita berada realitas kita ada di muka bumi merupakan perpanjangan identitas kita dan tentang siapa diri kita sesungguhnya. Unsur perubahan dinamis penting dalam sebuah dwelling. Pertama adalah wandering (mengembara/berpetualang) untuk memperluas definisinya berhuni. Berpikir dan berimajinasi sangat penting dalam petualangan hidup manusia yang tdk pernah berakhir. Kedua staying (tinggal) - dengan cara melihat dunia luar dari tempat tinggal kita. Ketiga, berhuni juga memerlukan akumulasi waktu, kumpulan pengalaman, yang didefinisikan sebagai proses pembelajaran, yang akan memberikan 
keterikatan seseorang pada suatu atau banyak tempat. Bahkan jika seseorang telah mempunyai sebuah berhuni untuk tinggal dan beristirahat, tetap ada kebutuhan untuk pergi dan berpetualang mencari pengalaman baru dan interaksi baru

\section{Industri}

Menurut Jack Rothman (1979), Pemberdayaan Masyarakat adalah sebuah model pengembangan masyarakat yang menekankan pada partisipasi seluruh masyarakat. Industri kecil adalah suatu kawasan usaha berskala kecil yang sederhana,tidak terkena kebijakan pemerintah karena perputaran usahanya kecil dijalankan sendiri.

\section{Komunitas}

Komunitas adalah suatu kelompok sosial atau suatu kumpulan nyata, teratur, dan tetap dari individu- individu yang melaksanakan peran-perannya secara berkaitan guna mencapai tujuan bersama (Puspito, 2008)

\section{Industri Konveksi}

Industri konveksi adalah suatu perusahaan yang menghasilkan pakaian jadi pakaian wanita, pria, anak, pakaian olahraga, maupun pakaian-pakaian partai politik . Industri konveksi termasuk kategori usaha kecil dansedang karena tenaga kerja yang sedikit. Garment merupakan suatu proses dimana kain atau barang setengah jadi dirubah menjadi barang jadi yang siap untuk dipakai. Perbedaan antara konveksi dan garment adalah terdapat dalam skala pemproduksiannya,luas wilayah, serta jumlah barang produksi.

\section{Alat Industri Konveksi}

Peralatan yang dibutuhkan dalam bisnis konveksi, meliputi mesin jahit, obras, overdeck, rantai, meja steam, meja potong, mesin potong dan peralatan menjahit seperti meteran, gunting, dan lain-lain.

a. Mesin Jahit Kecepatan Tinggi; Mesin jahit ini berkapasitas dinamo 5000 jahitan/menit dan bentuknya berbeda dengan mesin jahit rumahan. Kecepatannya juga cukup tinggi.

b. Mesin Potong; Dijalankan dengan tenaga listrik yang fungsinya memotong bahan dalam jumlah banyak agar Hasilnya lebih simetris dan akurat daripada memotong dengan tenaga manusia.

c. Mesin Obras Benang; Berfungsi untuk merapikan sisi potongan kain dengan rajutan benang sutra sebelum dijahit dengan benang kuat. Prosesnya memang harus dilakukan oleh ahli karena mesin ini juga akan memotong sedikit bagian sisi untuk diberikan rajutan.

d. Setrika Uap Gas; Setrika uap gas ini untuk merapikan bahan yang akan dijahit ke tingkat lanjutan (finishing) dan atau setelah busana jadi. Hasilnya busana lebih licin dan lembut

e. Setrika Uap Listrik; Setrika ini juga fungsinya sama dengan setrika uap gas namun dengan waktu yang lebih singkat

f. Mesin Press Uap; Mesin press uap ini memiliki tingkat ketelitian dan keselarasan lebih tinggi.

g. Mesin Pelubang Kancing; Untuk kebutuhan konveksi kaos dan kemeja, membutuhkan mesin pelubang kancing agar terlihat lebih rapi.

h. Mesin Pemasang Kancing; Mesin pasang kancing ini memang khusus untuk memasang kancing di tempat yang ditentukan. Jika kemeja dipasang kancing secara manual maka waktunya juga akan lebih lama.

i. Mesin Press Kancing; Untuk membuat kancing model menggunakan mesin press kancing yang lebih presisi dan hasilnya lebih bagus.

j. Mesin Jahit Serba Bisa; Mesin jahit ini bisa merangkul semua pekerjaan jahitan seperti obras, pasang kancing, bordir dan sebagainya. namun kelemahan dari mesin ini adalah dinamo yang kapasitasnya kecil sehingga waktu produksi lebih lama. 


\section{METODE}

Basic Design Methods oleh Karl Jomakka menyatakan bahwa metode desain harus dipilih sesuai dengan tantangan yang ada pada proyek tertentu dan bukannya tidak mungkin bahwa metode yang dipilih tersebut adalah bukan yang terbaik. terdapat 7 metode desain utama yang terbagi kedalam beberapa rincian metode tersebut adalah

\section{a. Nature and Geometry as Authorities}

Biomorgrophic Architecture Quadrature and Triangulation

b. Precedent

Typologi Transformation as a Specific model

c. Respon to Site

Regionalism Contextualism

d. Accident and the Unconscious as Sources

Heterotopis Surrealist Devices

e. Music and Mathematics as Models

Musical Analogies Higher Dimensions

f. Generative Processes

Superposition and Scalling

Morphing, folding, and Animate Form Datascape

Diagrams Parametric Design

\section{g. Rationalist Approaches}

Performance Form

Design Research

Dari metode - metode tersebut metode yang tepat dalam merancang program yang disusulkan adalah :

Respon to Site - Contextualism

Precedent - Transformation as a specific model

Pendekatan yang digunakan selain basic design method oleh Karl Jomakka adalah metode everydayness dengan memperhatikan keseharian para pekerja industri tekstil di sekitar Kawasan Perkampungan Industri Kecil Pulogadung. Konsep everydayness dilakukan demi menghasilkan karya arsitektur yang terkesan humanis dan masuk dengan konteks lingkungan sekitarnya yaitu industri kecil pada bidang tekstil. Maka metode yang mendukung adalah dengan melakukan pengumpulan data dan survey tapak di Perkampungan Industri Kecil Pulo Gadung. 


\section{DISKUSI DAN HASIL}

Dalam melakukan penelitian penulis melakukan metode survey tapak dan analisa pada kawasan PIK Pulo Gadung, dari hasil survey tersebut ditemukan bebrapa isu yang didapat berupa :

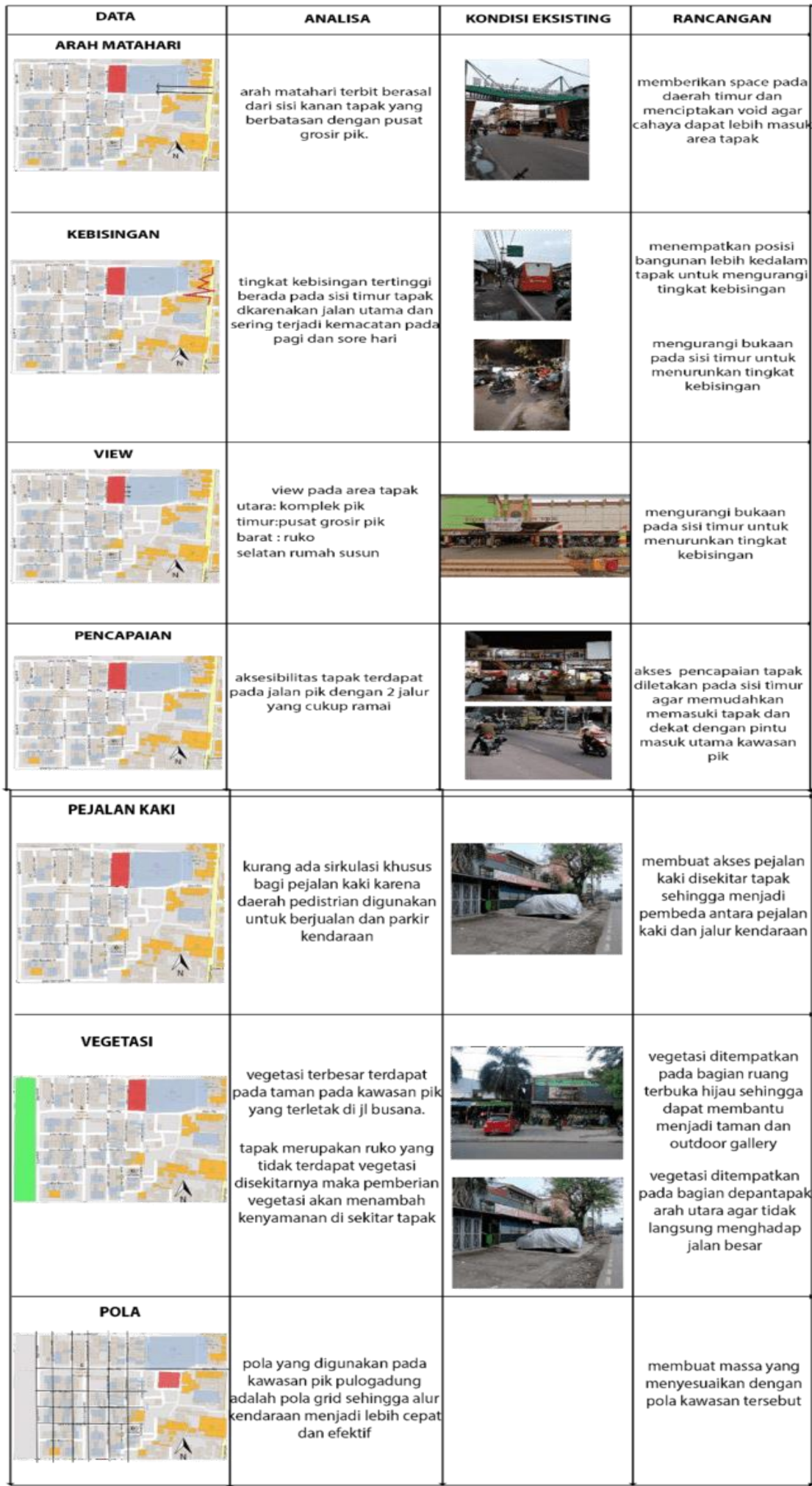

\section{Gambar 1. Analisa tapak}

Sumber : Penulis, 2020 


\section{Lokasi Tapak}

Lokasi : Jl raya PIK, Penggilingan, Kec. Cakung,

Kota Jakarta Timur, Daerah Khusus Ibukota Jakarta

Luasan : $2700 \mathrm{M}^{2}$

KECAMATAN : Cakung

KELURAHAN: Penggilingan

KODE BLOK : 07

ZONA : Pusat kegiatan primer, Kawasan sentra industri timur, Kawasan pengendalian pertumbuhan industri

KDB : 65

KLB : 1.96

KB $: 3$

$\mathrm{KDH}: 25$
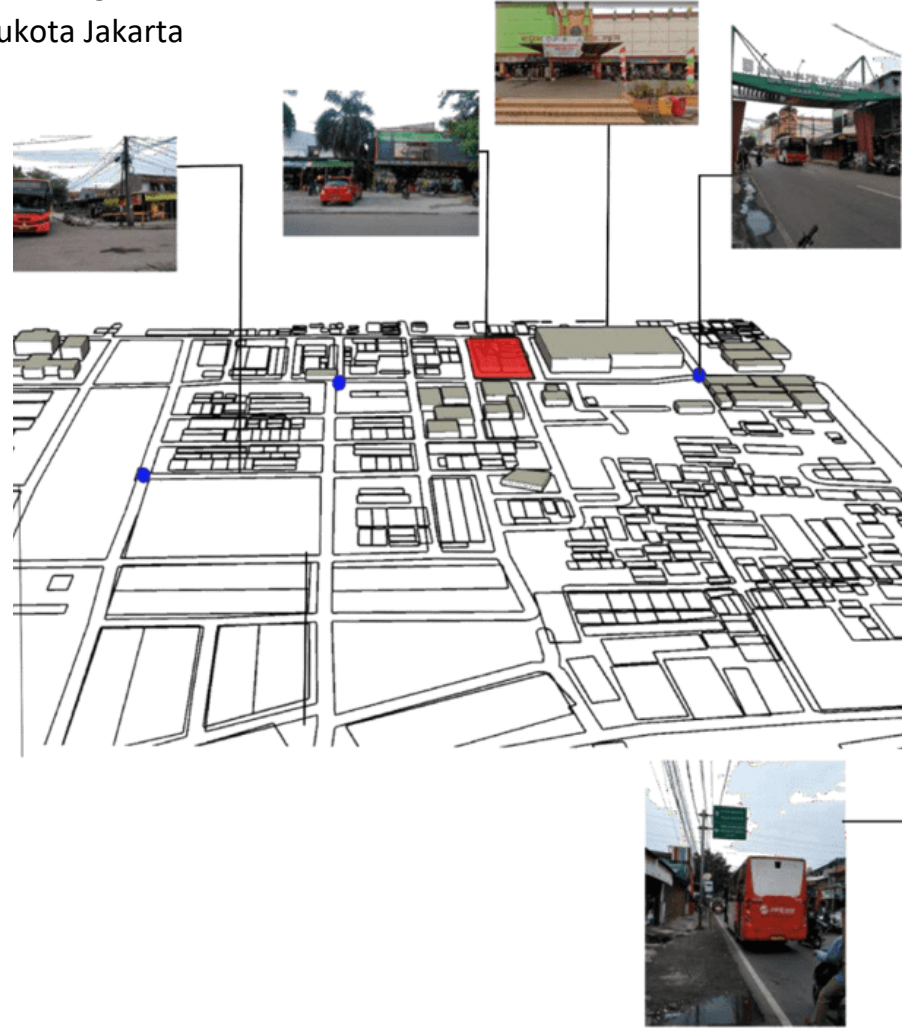

KTB : 60

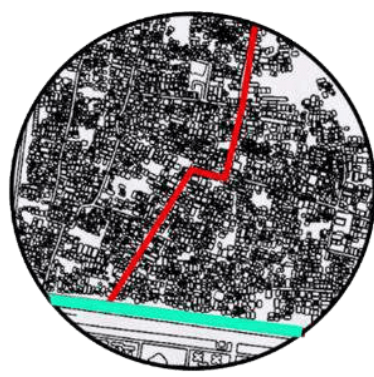

\section{AKSESIBILITAS}

Jarak dari Pulogadung menuju stasiun Klenderbaru $1.3 \mathrm{~km}$

Jarak dari Pulogadung menuju stasiun Buaran 1.5km

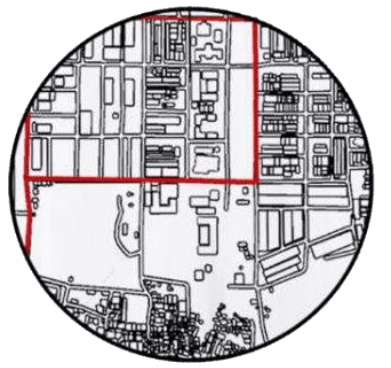

Dengan menggunakan bus feeder transjakarta

Pemberhentian pertama rute $11 \mathrm{D}$ bis adalah Pulogebang dan pemberhentian terakhir adalah Pulogadung 2

\section{Gambar 2 .Lokasi Tapak}

Sumber : Penulis, 2020 


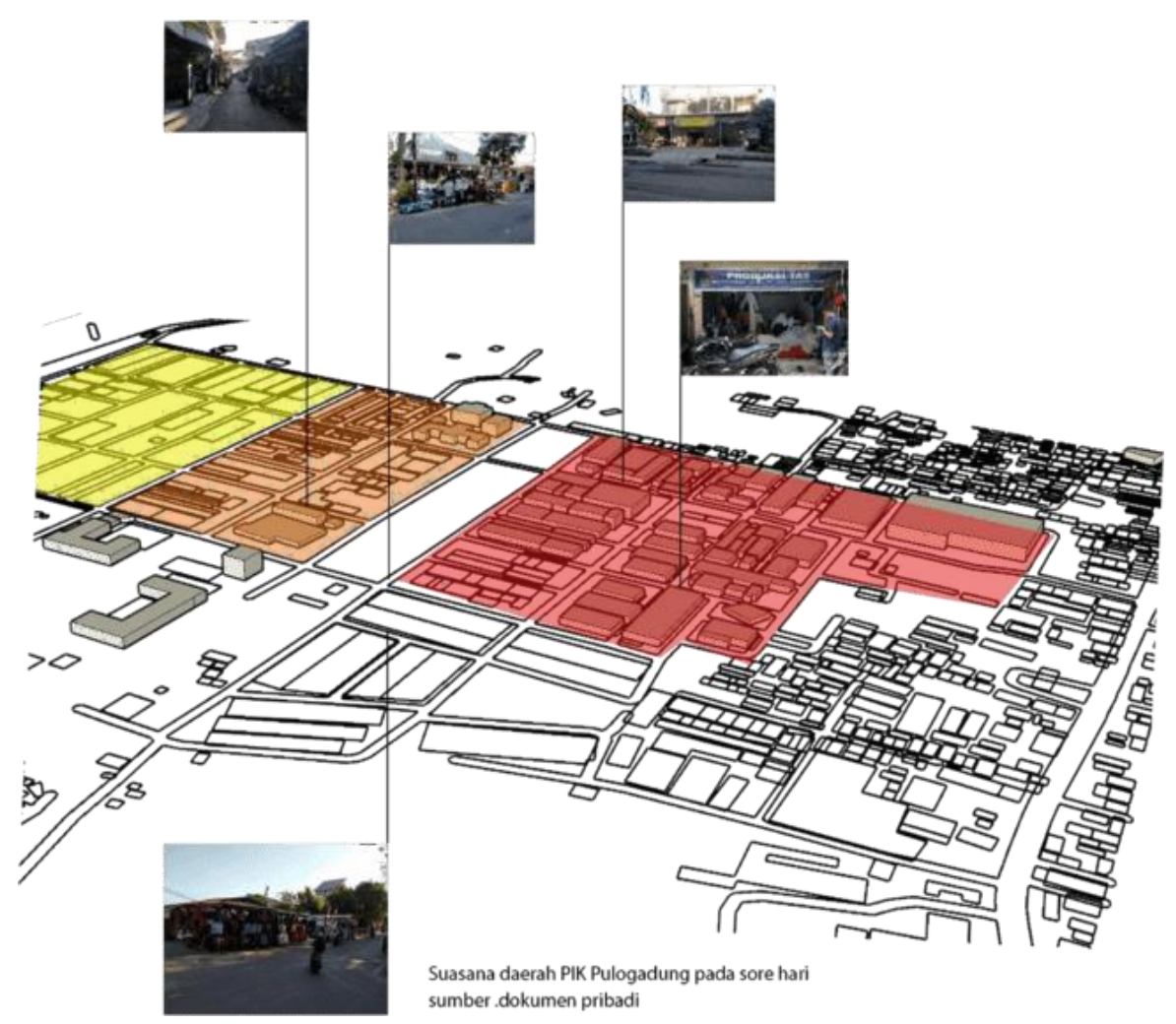

Gambar 3. Pembagian tapak

Sumber : Penulis, 2020

Daerah PIK Pulo Gadung terdapat 3 industri besar yang menempati pada titik tertentu seperti Kawasan : industri konveksi kecil, kawasan industri konveksi berskala besar, dan kawasan industri metal dan tekstile. Pada kawasan industri kecil para pekerja dan pemilik usaha bekerja di dalam ruko atau hunian mereka masing masing dengan alat yang sederhana dan jumlah produksi yang berskala kecil dan target pemasaran hanya di sekitar kawasan tersebut. Kawasan industri berskala besar memiliki bangunan yang luas dan memperkejakan banyak pekerja dengan jumlah produksi yang besar dan target pemasaran hingga ke luar daerah. Kawasan industri metal dan konveksi terletak pada bagian ujung kawasan karena menimbulkan suara yang cukup bising sehingga dapat mengganggu aktivitas sekitar kawasan.

\section{Proses Gubahan Massa}

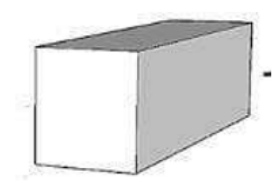

Massa awal berbentuk persegi Panjang mengikuti bentuk tapak

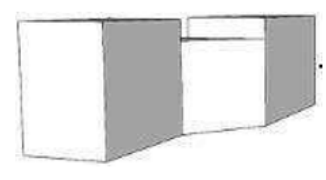

Massa dibagi menjadi 3 bagian dan mengalami pengurangan massa pada bagian tengah

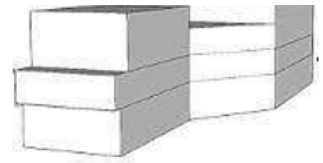

Massa mengalami pergeseran pada beberapa bagian

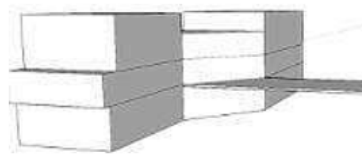

Hasil akhir gubahan massa berupa penambahan konektor penghubung menuju pusat grosir PIK

Gambar 4. Gubahan massa

Sumber : Penulis, 2020 


\section{Pembagian Zona}

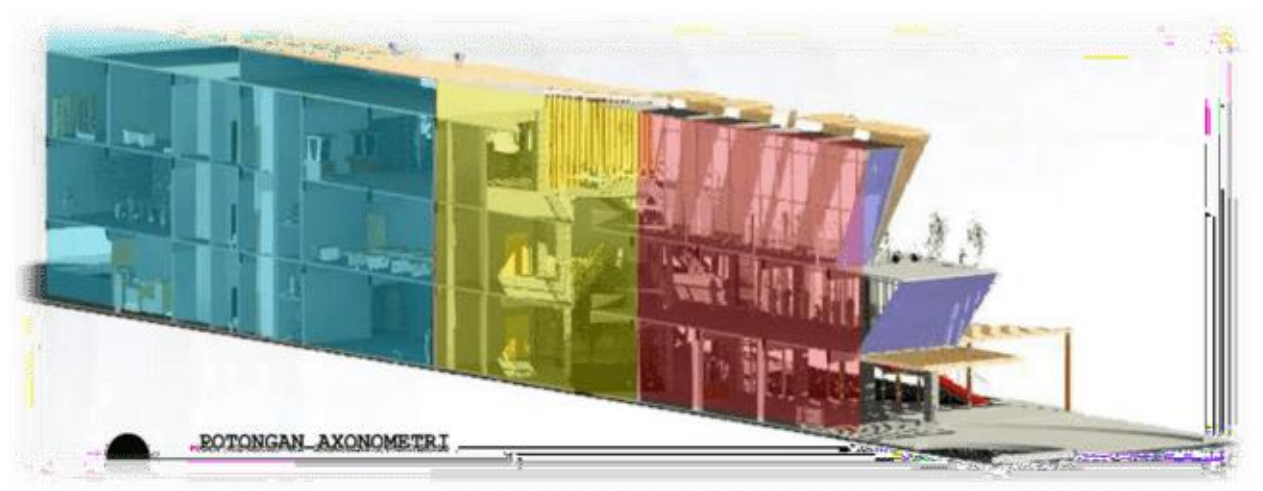

Gambar 5. Potongan axonometri

Sumber : Penulis, 2020

\begin{tabular}{|c|c|}
\hline & $\begin{array}{l}\text { lobby } \\
\text { Bazaar Exhibition } \\
\text { Outdoor gallery }\end{array}$ \\
\hline 2. & $\begin{array}{l}\text { blik : Lounge } \\
\text { Innercourtyard }\end{array}$ \\
\hline
\end{tabular}

\begin{tabular}{|ll|}
\hline 3. Area & Kelas \\
& Kelas jahit \\
& Kelas tekstil Studio \\
& desain Area \\
& finishing \\
& Kantor pengelola \\
& \\
\hline
\end{tabular}

\section{Program}

Berdasarkan hasil dari analisa kawasan dan tapak dapat disimpulkan bahwa kawasan merupakan kawasan industri khususnya industri tekstil maka program yang diusulkan untuk melengkapi hasil analisa tersebut adalah ruang komunitas pelatihan dan tempat pameran dengan berbagai fasilitas pendukung sebagai berikut :

Tabel 1. Program ruang

\begin{tabular}{|c|c|c|c|c|}
\hline NO & RUANG & LUASAN M ${ }^{2}$ & KAPASITAS & ALAT \\
\hline \multicolumn{5}{|c|}{ KELAS } \\
\hline 1 & KELAS TEORI & 240 & 20 & MEJAKURSI \\
\hline 2 & KELAS TEXTIL & 180 & 20 & MEJAKURSI \\
\hline 3 & KELAS PATTERN & 240 & 18 & MEJA GAMBAR \\
\hline 4 & KELAS DETAIL & 240 & 18 & MEJA GAMBAR \\
\hline 5 & KELAS JAHIT & 180 & 20 & MEIA JAHIT KURSI \\
\hline \multicolumn{5}{|c|}{ WORKSHOP } \\
\hline 6 & STUDIO JAHIT & 180 & 20 & MEIA JAHIT KURSI \\
\hline 7 & STUDIO DESAIN & 240 & 18 & MEJA GAMBAR \\
\hline 8 & STUDIO FINISHING & 240 & 18 & MEJA GAMBAR \\
\hline 9 & GUDANG BAHAN & 200 & 20 & \\
\hline 10 & GUDANG ALAT & 200 & 20 & \\
\hline 11 & EXHBBTION & 400 & 40 & \\
\hline 12 & MARKET & 200 & 20 & \\
\hline 13 & OUTDOOR GALLERY & 400 & & STAN GALLERY \\
\hline 14 & LOKER PRIA & 20 & 10 & LOKER \\
\hline 15 & LOKER WANITA & 20 & 10 & LOKER \\
\hline \multicolumn{5}{|c|}{ PENGELOLA } \\
\hline 16 & MANAGER & 20 & 4 & MEIA KURSI \\
\hline 17 & SEKRETARIS & 20 & 5 & MEIA KURSI \\
\hline 18 & TIM PELATIHAN & 40 & 10 & MEIA KURSI \\
\hline 19 & TATA USAHA & 20 & 5 & MEIA KURSI \\
\hline 20 & BENDAHARA & 20 & 5 & MEAA KURSI \\
\hline 21 & RUANG RAPAT & 60 & 10 & MEIA KURSI \\
\hline \multicolumn{5}{|c|}{ SERVIS } \\
\hline 22 & TOILET PRIA & 20 & 10 & \\
\hline 23 & TOLLET WANITA & 12 & 7 & \\
\hline 24 & PANTRY & & & \\
\hline \multicolumn{5}{|c|}{ MEP } \\
\hline 25 & GENSET & 50 & & \\
\hline 26 & TRAFO & 18 & & \\
\hline 27 & STP & 32 & & \\
\hline 28 & GWT & 32 & & \\
\hline \multicolumn{5}{|c|}{ PARKIR } \\
\hline 30 & PARKIR MOBIL & & & \\
\hline 31 & PARKIR MOTOR & & & \\
\hline 32 & LOADING DOK & & & \\
\hline & TOTAL & \multicolumn{3}{|c|}{$3724 \mathrm{~m} 2$} \\
\hline
\end{tabular}

Sumber : Penulis, 2020 


\section{Konsep}

Konsep bangunan ini adalah

Transparan dengan hubungan ruang yang dinamis.transparan yang dimaksud adalah transparan secara keseluruhan transparan pada konsep ini menggambarkan proses penjelasan mengenai industri tekstil yang dimulai dari tools, supporting, hingga hasil akhir berupa finishing yang terlihat secara keseluruhan dari luar bangunan.

Transparan dalam arsitektur dibagi menjadi 2 yaitu :

1. Terbuka pendekatan terbuka pada bangunan akan terasa seperti menyatu antara interior,organisasi ruang dan fasad bangunan tersebut

2. Hubungan ruang memiliki hubungan ruang disekitarnya seperti pembagian yang didasari fungsi ruang

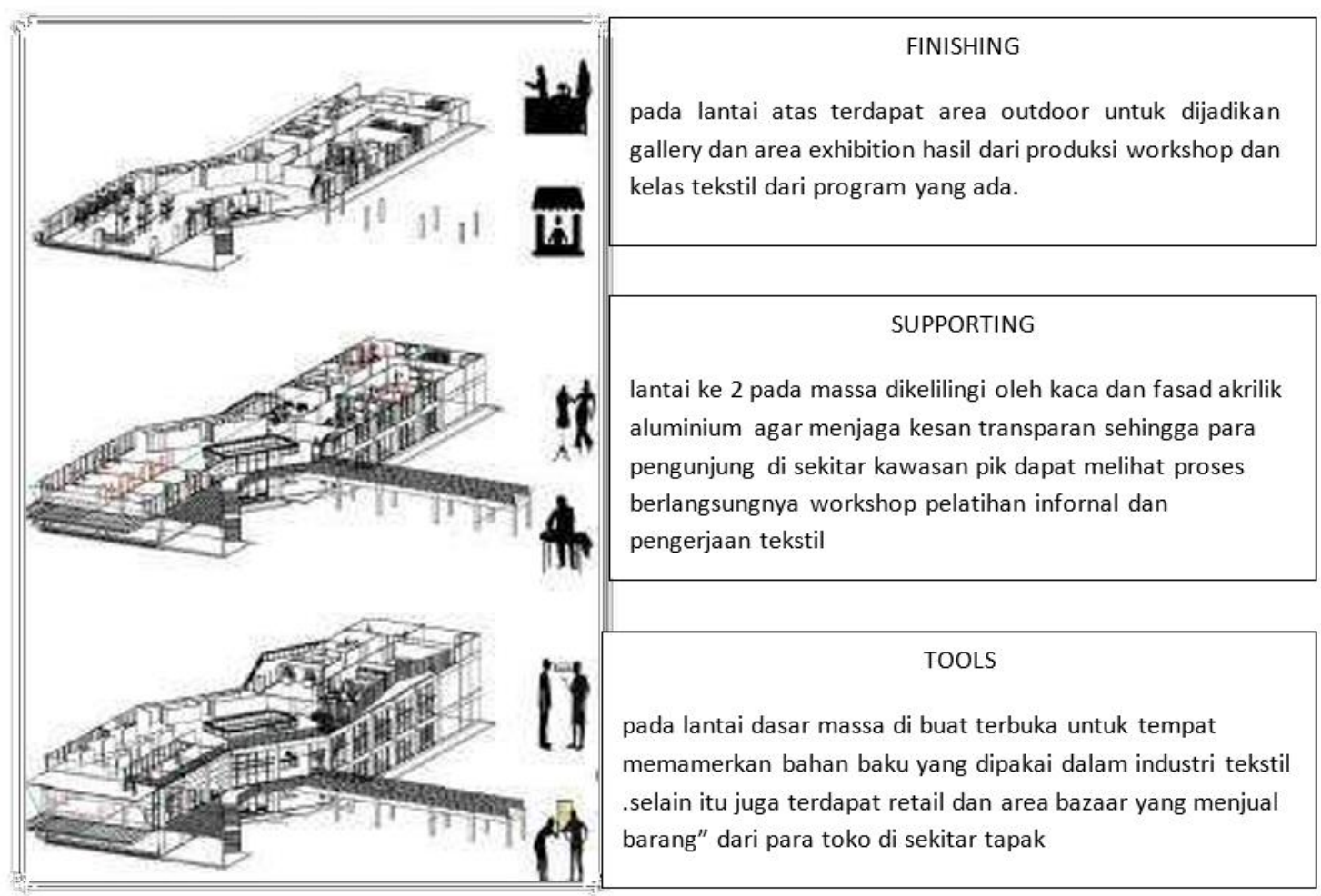

Gambar 6. Konsep bangunan

Sumber : Penulis, 2020 


\section{Hasil Rancangan}

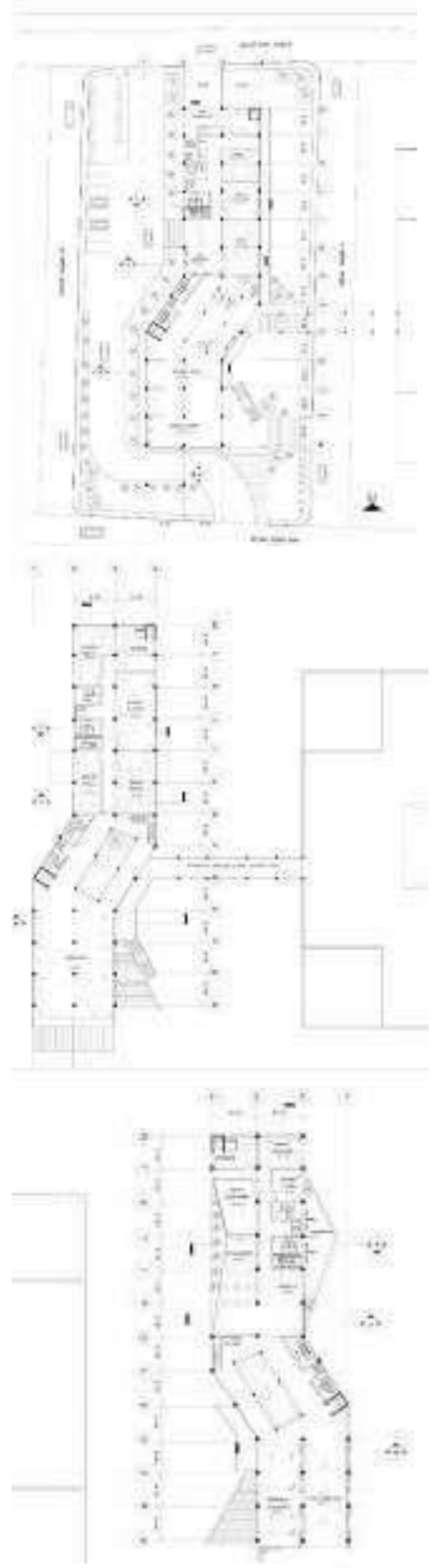

Gambar 7. Denah bangunan

Sumber : Penulis, 2020
Pada lantai 1 terdapat 2 area entrance utama menuju lobby bazaar dan lobby pelatihan dan terdapat 1 pintu samping yang menghubungkan antara courtyard dan atrium pusat grosir PIK.

Selain 3 entrance tersebut juga terdapat tangga outdoor yang dapat langsung menuju gallery pada lantai 2 dan terkoneksi dengan jembatan penghubung menuju area grosir PIK.

Pada area lantai 2 terdapat jembatan penghubung yang menghubungkan antara atrium pusat grosir perkampungan industi kecil dan area courtyard menuju gallery dan area pelatihan.

Pelatihan yang diadakan pada bangunan ini bersifat pelatihan informal yang ditunjukan bagi para pengunjung dan pekerja usaha tekstil kecil untuk lebih meningkatkan teknik teknik dasar dalam menjahit dan lebih mengekspresikan diri dalam bidang fashion sehingga dapat dipamerkan dalam gallery yang terdapat pada lantai 2 .

Area lantai 3 terdapat area exhibition yang bertujuan sebagai tempat pameran dari hasil pelatihan tekstil dan jahit seperti pakaian, tas,dan sepatu hasil karya dari para peserta dan pekerja dibidang industri kecil tekstil.

Selain area exhibition pada lantai 3 juga terdapat area cafetaria dan lounge sebagai tempat beristirahat bagi para pengunjung dan perserta pelatihan. 


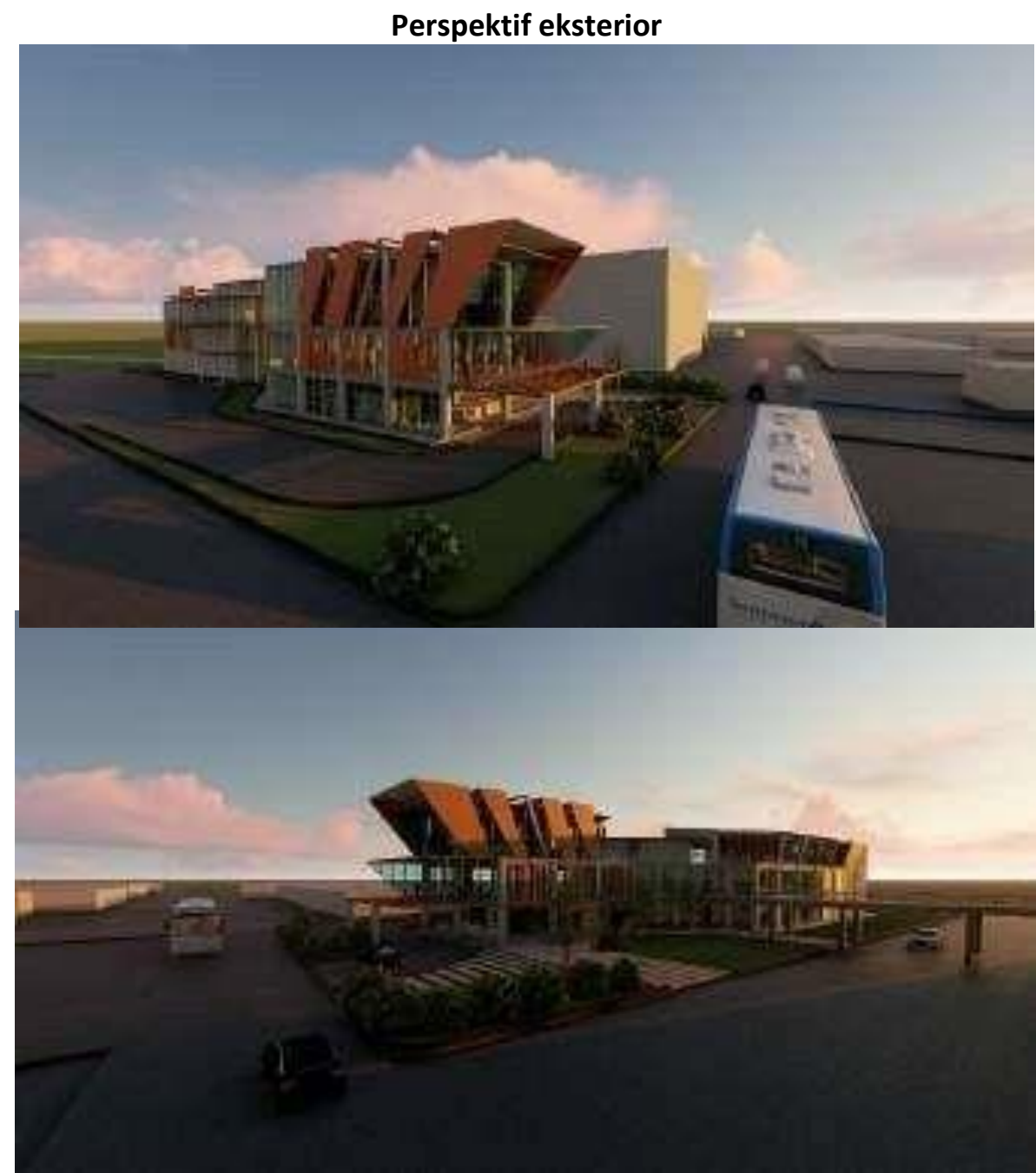

Gambar 8. Perspektif bangunan

Sumber : Penulis, 2020

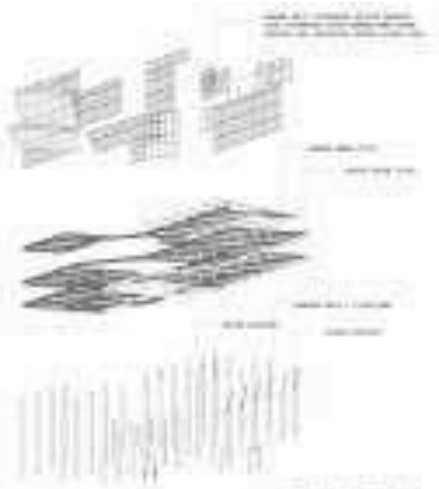

Struktur utama pada bangunan ini adalah kolom beton $60 \times 60$ dengan balok induk 30/60 dan balok anak 25/50

Keseluruhan bangunan ini menggunakan rangka kaca untuk memberikan kesan terbuka dan terhubung dengan ruang luar .

Fasad pada bangunan menggunakan material powder coated metal 


\section{Perspektif Interior}

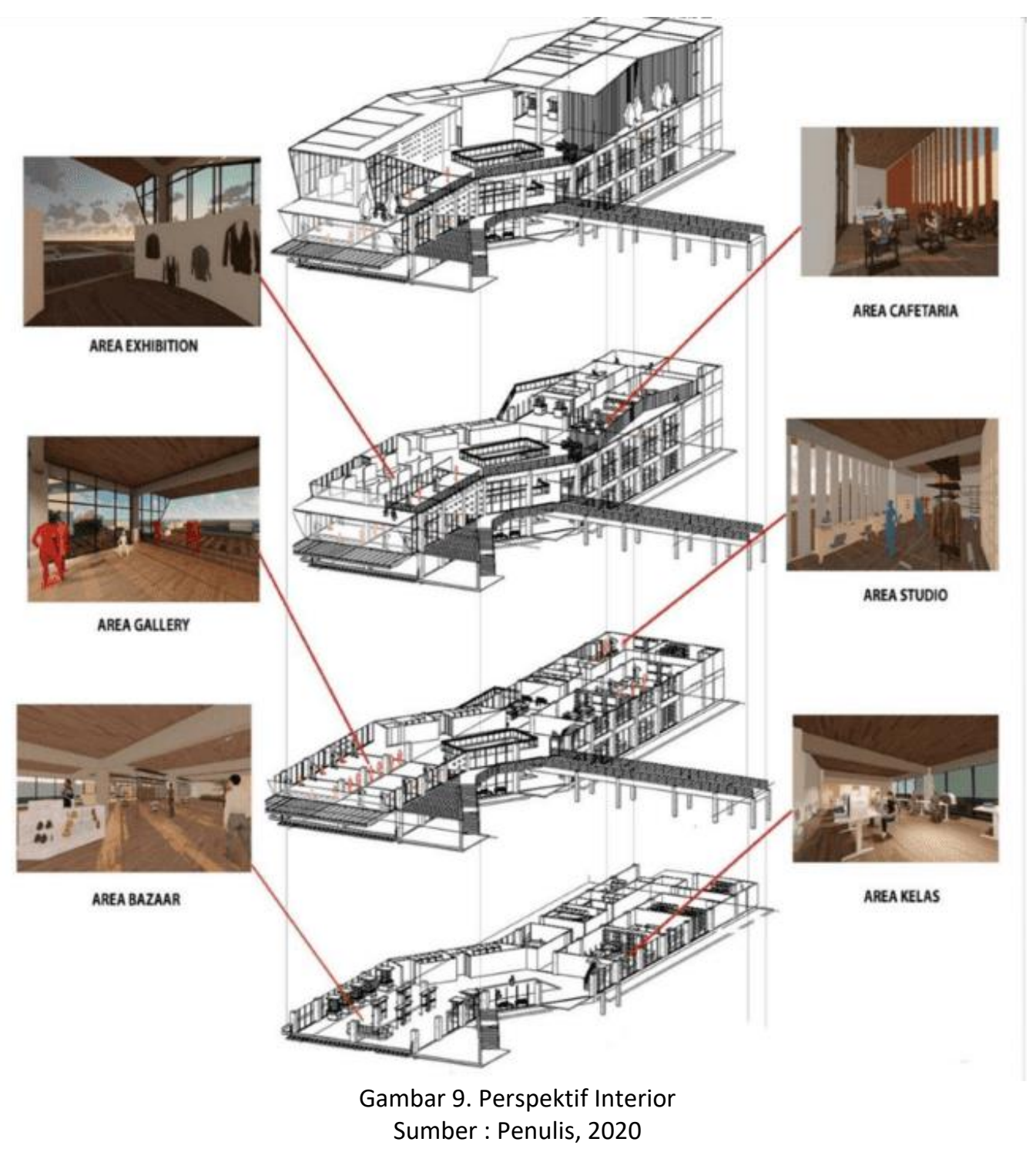

\section{KESIMPULAN DAN SARAN Kesimpulan}

Dengan banyaknya orang yang berdatangan ke kota besar banyak terdapat Indsutri kecil seperti pada kegiatan industri kecil di Pulo Gadung, Penggilingan Cakung, namun seiring meningkatnya para pendatang dan kurangnya pengendalian dalam pengelola industri kecil maka banyak orang tidak dapat memanfaatkan potensi yang ada dan kurangnya pelatihan sehingga berakhir dengan meningkatnya pengangguran di kota kota besar. Dengan banyaknya pengusaha industri kecil pada bidang tekstil maka untuk merespon wilayah sekitar perlu menyediakan wadah untuk memperlhatkan karya karya industri kecil dan menarik para pengunjung sekitar Kawasan PIK Pulo Gadung ,selain untuk meningkatkan kualitas dalam industri kecil tetapi juga untuk menciptakan sumber lapangan pekerjaan baru.

\section{Saran}

Tujuan penyusunan laporan perancangan ini adalah untuk meningkatkan kualitas dan kreativitas dalam industri kecil khususnya dibidang industri tekstil agar industri kecil dapat lebih dilihat oleh banyak orang dan lebih bersaing dibidang industri tekstil. 


\section{REFERENSI}

Norberg-Schulz, C. (1985). The Concept of Dwelling: on the way to figurative architecture. New York : Rizzoli

Ching , F. D. K. , (2008). Ilustrasi Desain Interior. Jakarta: Penerbit Erlangga.

Heidegger, M. (1999a). Building Dwelling Thinking. In David Farrell Krell (Ed.), Basic Writings Martin Heidegger (pp. 347-363). London: Routledge.

Jomakka, K., (2007). Basic desain method. Basel: Birkhauser architecture

Puspito, H. (2008). Pengertian komunitas. Yogyakarta.

Panero \& Julius. (2005). Dimensi manusia dan ruang. Jakarta: Penerbit Erlangga.

Rothman, J. (1979). Occupational Roles: Power and Negotiation in the Division of Labor. The Sociological Quarterly. 20 (4). 495-515. https://doi.org/10.1111/j.15338525.1979.tb01231.x

Archdaily," Gennevilliers Training Center" „Brenac Gonzalez, dilihat tanggal 23/10/2020, (https://www.archdaily.com/384968/gennevilliers-training-center-atelier-darchitecture-brenac-gonzalez).

Archdaily,"Xinhee Design Center", Mad architects, dilihat tanggal 23/10/2020, (https://www.archdaily.com/792988/mad-architects-design-veiled-xinhee-designcenter- in-xiamen).

Archdaily,"Tooker State University", SCB architects, dilihat tanggal 23/10/2020 (https://www.archdaily.com/882217/tooker-house-at- arizona-state-universityscb/59eeb36bb22e38649800011f-tooker-house-at-arizona-state-university-scb-selfshading-diagram).

Berkaos.com ,"Alat Mesin Konveksi", Berkaos.com,23/10/2020, (https://berkaos.com/bisniskonveksi-kaos-mesin-yang-dibutuhkan 
